\title{
Smart Arduino Sensor Integrated Drone for Weather Indices: Prototype
}

\author{
Hanping Mao, Oppong K. Paul, Ning Yang and \\ Lin Li
}

Additional information is available at the end of the chapter

http://dx.doi.org/10.5772/intechopen.76872

\begin{abstract}
Mostly, the conditions within an ecosystem as well as weather of a field affect crop productivity greatly. Different weather conditions produce different effects and different impact on the quality of the crop field or the ecosystem. Weather elements form a chain reaction, as the atmosphere is not the only one being affected. Atmospheric air temperature, vapor pressure and relative humidity or moisture content can act together and form diverse effects on crops. These diverse effects turn to reduce radiation which is necessary for plants, or increase rainfall patterns. Consistent high temperatures can increase the heat transfer to local bodies of water in addition to heating the air. Monitoring the climate and the weather conditions are important not only as an environmental baseline, but to maintain quality working conditions, marine studies and recreational safety. The parameters of climate are measurable, for example, atmospheric vapor pressure, temperature, precipitation and solar radiation, can be captured and recorded daily on the Smart Arduino Sensor Integrated Drone. Means and extreme datasets, maximum and minimum weather trends with deviations of lengthy time series would be calculated for each of these climate parameters which were considered in this study. These results are a simple form of climate indices, as they already describe changes in climate. All the readings and datasets are recorded on a cloud platform, as well as, in an installed microchip on the drone. Data synchronization is done with MAT-LAB and Arduino Programming Rule.
\end{abstract}

Keywords: Arduino, MATLAB, sensor, weather data, rain-cap, wind-cap, environment

\section{Background to the proposed work}

Climate and weather data monitoring which gives vivid and exact information for farming purposes goes beyond weather stations. Interesting enough, every farmer needs to know and monitor the weather if high productivity is to be met. 
Research has it that, agricultural productivity relies directly and indirectly on the weather and climatic conditions. Therefore failure to adhere to the weather before, during and after farming renders crop production susceptible to unsuspected disease attacks that are caused or influenced by certain weather conditions [1]. This research is intended to meet the demand for easy-to-use, easy-to-access, and accurate weather data for farmers using a drone (UAV) with mounted Arduino Sensors to give accurate climate information to farmers in crop production especially rainfall, solar (duration and intensity) and temperature.

This Arduino Drone is been built and developed in Jiangsu University-Zhenjiang, China P.R, with state-of-the-art multi-parameter weather sensors which focus on four main weather parameters - radiation, temperature, rainfall, and humidity all in one compact, lightweight instrument called Smart Arduino Drone. There are readings for other weather parameters but the focus is on the above four data set as they have direct or indirect effect on crops at a higher rate considering rice production in Zhenjiang, China.

This Smart Arduino Drone is built with easy setup and synchronization with the controller and stored memory for computer reading and analysis. It will need minimal technical knowhow to install, integrate, and maintain. The main focus is to monitor the weather conditions on a rice field, tea farm, maize or vegetable fields as these crops require different conditions for optimal productivity.

The Arduino Board which controls the sensors runs on the Arduino Software and MATLAB data logins and it will give users an automatic data collection and the option of real-time data posting through the Internet due to the onboard GPS (Beidou) system.

\subsection{Aims and objectives}

This study mainly focuses on developing a high-resolution weather data indices for farmers using a Smart Drone. Again the Smart Drone is designed to record accurate weather readings which are far less labor-intensive over the traditional, manual counterpart of weather data recording at a weather station.

Specifically, this study seeks to estimate missing values in weather data by regularized expectation maximization also called RegEM, and to homogenize weather dataset by Quantile Matching Adjustment, referred to as QMadj [2].

\subsection{Evidence of research or justification}

\subsubsection{Surface climate and data reconstruction}

Climate data provide great depth of information about the atmosphere that impacts almost all ecosystem of human life [3]. Global change research and impact studies are highly dependent on the description of the mean state and variability of recent climate [2]. As such, continuous and quality climate datasets are precursors for excellent climate-impact studies especially for modern farmers. An example is the indication by [4] that high spatial and temporal rainfall resolutions were needed for urban drainage and urban flood modeling applications. 
Various mathematical approaches have been applied widely for data reconstruction in many climate datasets. This project will give first-hand information to the farmer directly on the farm and crop performances can be monitored. Herman et al. [5] constructed a comprehensive archive of Australian rainfall and climate data from ground-based observational data using spatial interpolation algorithms, so this project is justified due to the new way and method of monitoring the weather parameters for crop production.

\section{Materials and method}

\subsection{Materials}

- Site: Zhenjiang rice fields

The Drone considered for this project is DJI with Model Number Matric 600, Phantom 4 Pro. This drone is built to carry up to 13 pounds and produce all the thrust needed by relying on six rotor systems with each been powered by an actively cooled motor [6]. The Drone controller is an A3 Flight with six separate batteries that switches on automatically should one fail [6].

Arduino Board and Sensors: Temperature, Relative Humidity, Precipitation/Rainfall and Solar radiation (Duration \& Intensity), Beidou, Wind Sensor (Speed and Direction), and Digital Camera. Software is Arduino Programmer, and Mat Lab for Data Synchronization.
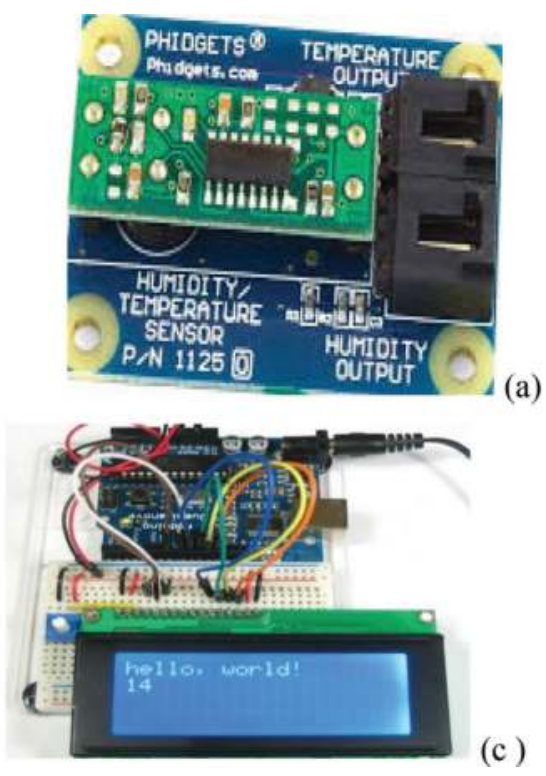

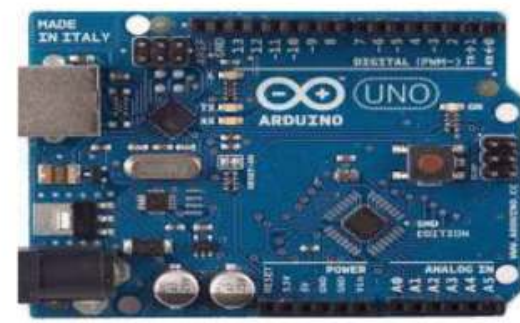

(b)

Figure 1. (a) Temperature and humidity sensor, (b) Arduino board mount, (c) Arduino board mount. 


\subsubsection{Methodology and scope of the project}

The Smart Arduino Sensor Drone will fly and record weather data and communicate the information to the farmer (Crop Production Fields) directly on a computer. The Arduino Sensor and the drone has been designed to quickly discover the key weather elements to making a successful farming with requirements to rice, tea, maize and some selected vegetable fields. It is been built as a hands-off, easy to use and as industry specific as possible.

First, The Arduino Board called TuxCase would be mounted on the base plate of the built UAV (Drone) using the flat-head screws. After this, the Arduino sensors would be placed inside the TuxCase as shown in Figure 1a-c [7], and fastened into the case using the four shorter (1/4") screws that came with the Arduino TuxCase kit.

Secondly, the colorimeter shield would be mounted onto the Arduino board which has only one orientation possible together with the weather parameter sensors by following the shield pins which are labeled on the silkscreen (white text) to match the label on the corresponding header on the Arduino board (Figures 2-4).

The synchronization process would be done using the Arduino Programming Rule, all the four sensors would be programed to record the weather information which will then be stored on a cloud and an installed microchip. The weather parameters of interest (rainfall, temperature, humidity and solar) would then be captured by the Arduino Sensors and processed by

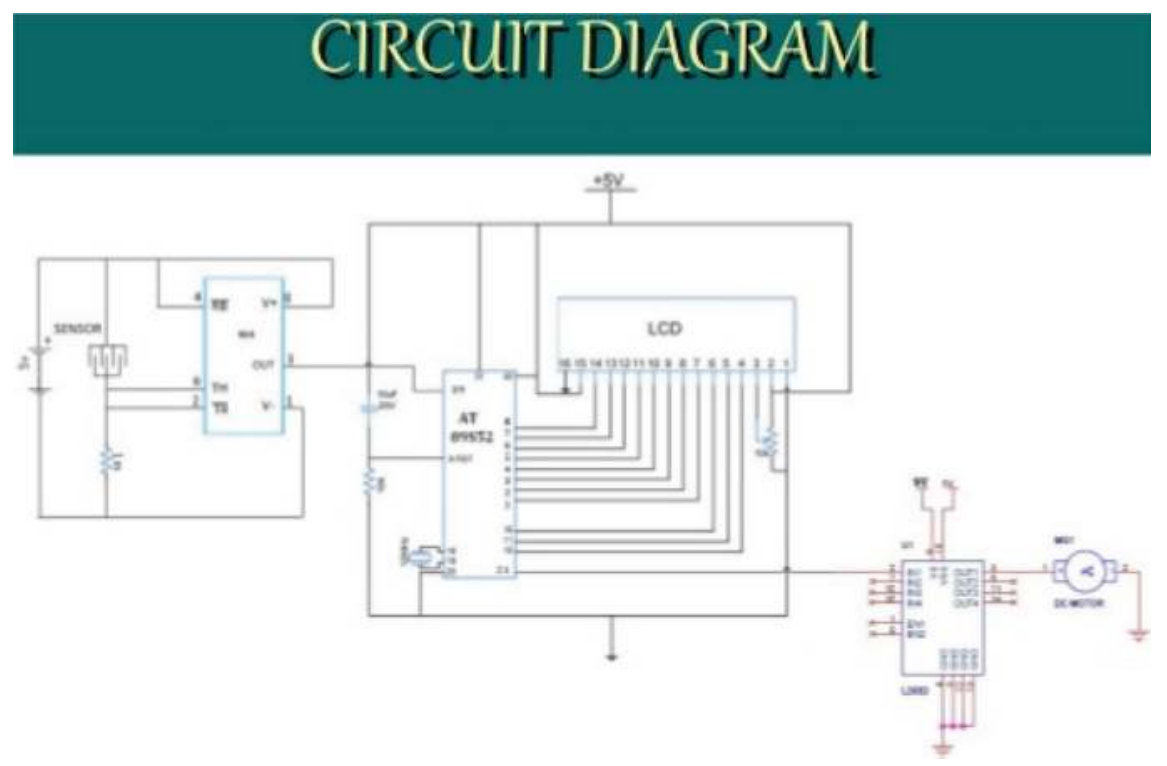

Figure 2. Circuit diagram for Arduino Connection. 


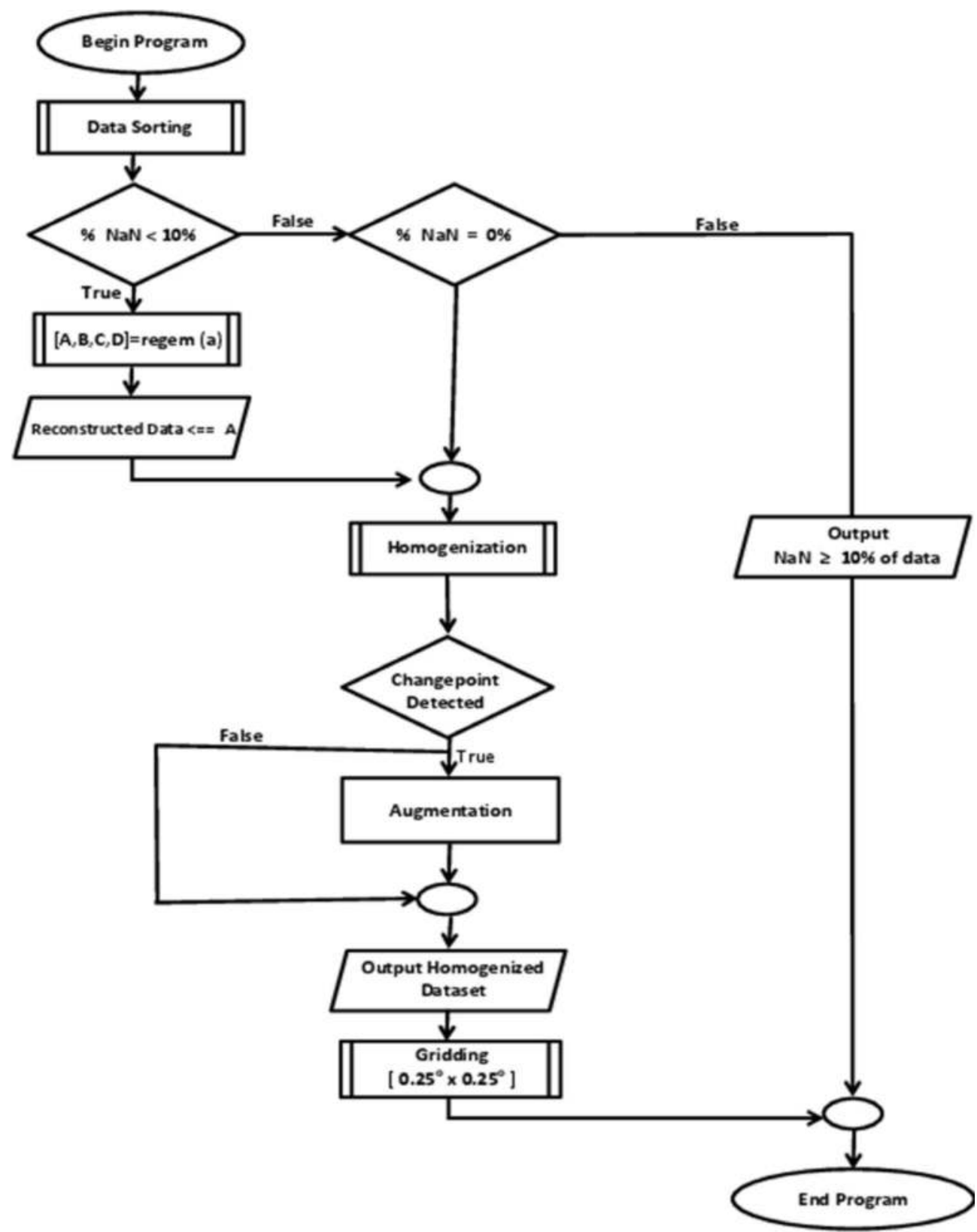

Figure 3. Arduino Programming Rule Interface: Flowchart of data gap estimation, homogenization and gridding steps that will be carried out in this study. 


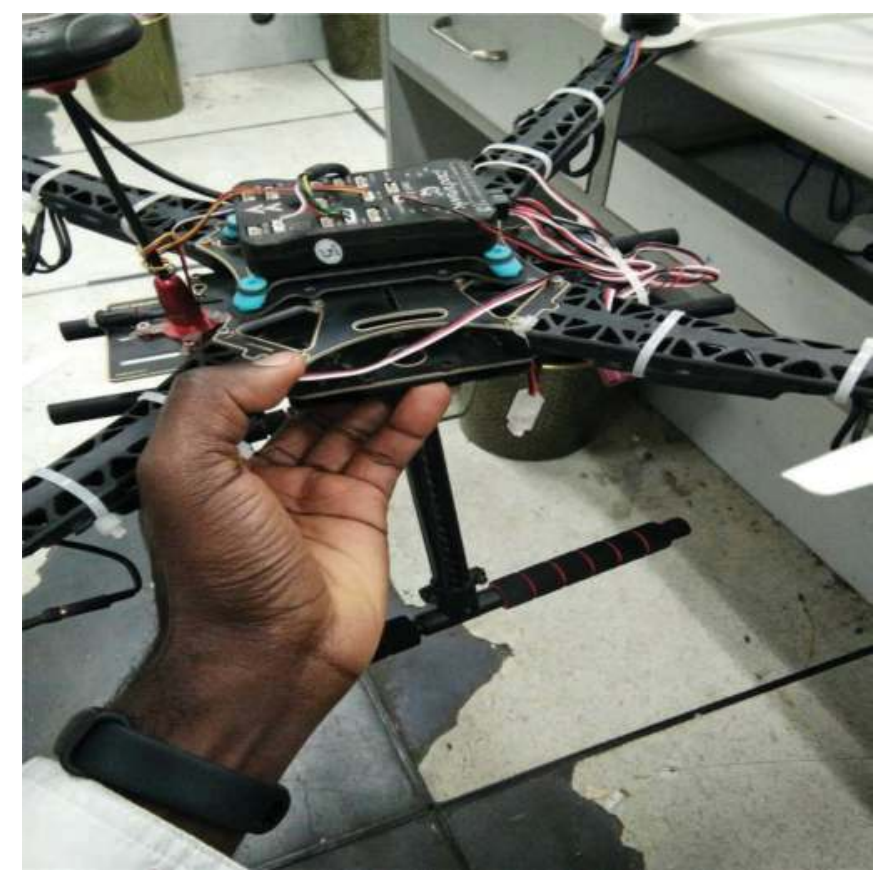

Figure 4. Smart Arduino sensor integrated drone.

MATLAB Software. The frequencies at which weather data can be collected, its quality and its ability to be processed, managed and stored becomes critical to how useful this Smart Arduino Sensor can be.

\subsection{The Arduino and MATLAB programing}

The structure of the Arduino programming language runs in at least two parts. These two required parts, or functions, enclose blocks of statements [8]. The setup function should follow the declaration of any variables at the very beginning of the program.

\subsection{Data captured by the Smart Arduino drone}

- Rainfall (intensity, and duration) would be measured using the Arduino RAINCAP Sensor, which is the only maintenance-free rainfall sensor. The rainfall sensor measures raindrops. The impacts will give signals which will be proportional to the intensity of the drops. The sensor will then convert the signal from each drop into rainfall, intensity, and duration. This RAINCAP sensor can even distinguish different types of rain such as Relief or Frontal [9].

- Temperature, relative humidity these sensors rely on Arduino's proven technology and experience, and provide highly accurate and stable readings based on the geological location of the flying drone. The unit calibration is done using the Arduino Software. 
- Solar (duration and intensity), wind speed and direction are measured ultrasonically with Arduino's advanced WINDCAP sensor and Solar sensor.

All the sensors within the Smart Arduino Drone would be calibrated using the Arduino Software and data analysis done by MATLAB. After all the sensors are mounted on the Arduino board, the Smart Arduino Drone needs to be aligned, connected to a data logger (computer) and power source (Battery). Flying height of the drone depends on the individual but it is estimated that, flying higher allows you to cover more ground in a shorter amount of time with less battery usage.

\section{Expected results: auto piloting sample}

From the table above (Table 1), the Smart Arduino Drone on trial recorded data in Zhenjiang indicating that, Zhenjiang is a warm temperate ecological zone. The data used (Table 1) shows that, there is significant rainfall throughout the year in Zhenjiang.

Even the driest month still has a lot of rainfall. According to [10], this climate is classified as Humid Tropical Climate (Cfa). The average annual temperature is $15.5^{\circ} \mathrm{C}$ in Zhenjiang.

Monthly rainfall totals of the four districts are presented with each entry representing the probable range of monthly rainfall total for any grid that lies within a particular zone. Dantu district records monthly rainfall peaks of about $300 \mathrm{~mm}$ in any of the months between June and September. Jurong District the zone with the overall highest cumulative rainfall amount

\begin{tabular}{|c|c|c|c|c|}
\hline \multirow[t]{2}{*}{ Month } & \multicolumn{3}{|c|}{ Rainfall (mm) } & \multirow[b]{2}{*}{ Yangzhong } \\
\hline & Dantu & Danyang & Jurong & \\
\hline January & $<100$ & $<100$ & $<100$ & $<100$ \\
\hline February & $<100$ & $<100$ & $<150$ & $<100$ \\
\hline March & $<150$ & $<150$ & $<250$ & $<150$ \\
\hline April & $50-200$ & 50-200 & $100-250$ & 50-200 \\
\hline May & 50-200 & 50-200 & $100-350$ & $100-250$ \\
\hline June & $100-300$ & $100-300$ & $150-450$ & $100-300$ \\
\hline July & $100-300$ & $100-300$ & $100-250$ & $<200$ \\
\hline August & $100-300$ & $100-300$ & 50-200 & $<150$ \\
\hline September & $50-300$ & $50-300$ & $50-300$ & $<150$ \\
\hline October & $50-150$ & 50-200 & $50-300$ & $<200$ \\
\hline November & $<100$ & $<100$ & $<200$ & $<100$ \\
\hline December & $<100$ & $<100$ & $<100$ & $<100$ \\
\hline
\end{tabular}

Table 1. Autopiloting estimates of monthly rainfall in four districts of Zhenjiang. 


\begin{tabular}{lllll}
\hline Month & \multicolumn{5}{c}{ Rainfall $(\mathbf{m m})$} & Yangzhong \\
\hline Dec-Jan-Feb & Dantu & Danyang & Jurong & $<400$ \\
Mar-Apr-May & $<300$ & $<300$ & $<400$ & $100-700$ \\
Jun-Jul-Aug & $100-500$ & $100-500$ & $100-900$ & $200-600$ \\
Sep-Oct-Nov & $200-800$ & $200-800$ & $300-800$ & $100-500$ \\
Annual & $200-600$ & $200-600$ & $200-800$ & $600-1400$ \\
\hline
\end{tabular}

Table 2. Autopilot estimates of seasonal \& annual rainfall in the four districts (agro-ecological zones).

(450 mm) amongst the four districts of Zhenjiang agro-ecological zones, whereas Yangzhong district is the zone with the least cumulative rainfall amount.

Yangzhong district has rainfall pattern similar to that of Jurong district, however, rainfall amounts over the Yangzhong district is lesser.

Table 2 shows autopilot estimates of seasonal rainfall totals for the four agro-ecological zones, with each column representing the range of rainfall total for any grid lying within a particular zone. Jurong district (zone) has an all-year maximum seasonal rainfall, with Yangzhong district recording the least seasonal rainfall. In all districts, the second trimester was found to be the rainfall onset over the country and thus, is the best season for farmers to engage in planting.

The third trimester, is identified as the season of probable extreme events over the entire Zhenjiang, and the very first trimester, however, is the driest period over the entire Zhenjiang.

\subsection{Success criteria: autopilot clearness index over Zhenjiang}

The transparency of the atmosphere over Zhenjiang is an all-important parameter, for the solar radiation potential of the city. It is indicated by the fraction of extraterrestrial solar radiation which reaches the earth surface as global radiation, and thus is a measure of the degree of the clearness of the sky, or the clearness index [11]. Figure 5 shows the clearness index over Zhenjiang for both Smart Drone estimated and weather station datasets.

It is shown in Figure $\mathbf{5 b}$ that clearness index has an estimated value greater than $50 \%$ for all the four agro-Meteorological zones or districts. The monthly average maximum and minimum estimated clearness index for the study area is 59 and $47.8 \%$.

This indicates a moderately transparent sky across the Zhenjiang city. Jurong district however, shows the lowest clearness index value of $54 \%$. This is not unexpected as it can be attributed to a bi-modal heavy rainfall and very low temperature regimes over the district [12]. The atmosphere here is thus characteristically moisture gladdened, with relatively high convective atmosphere. This affords the district a greater effect of atmospheric attenuation hence low atmospheric transparency.

The implication of having mean clearness index greater than $50 \%$ is that the sky is moderately transparent throughout the study area (Zhenjiang), confirming clear sky conditions and show 

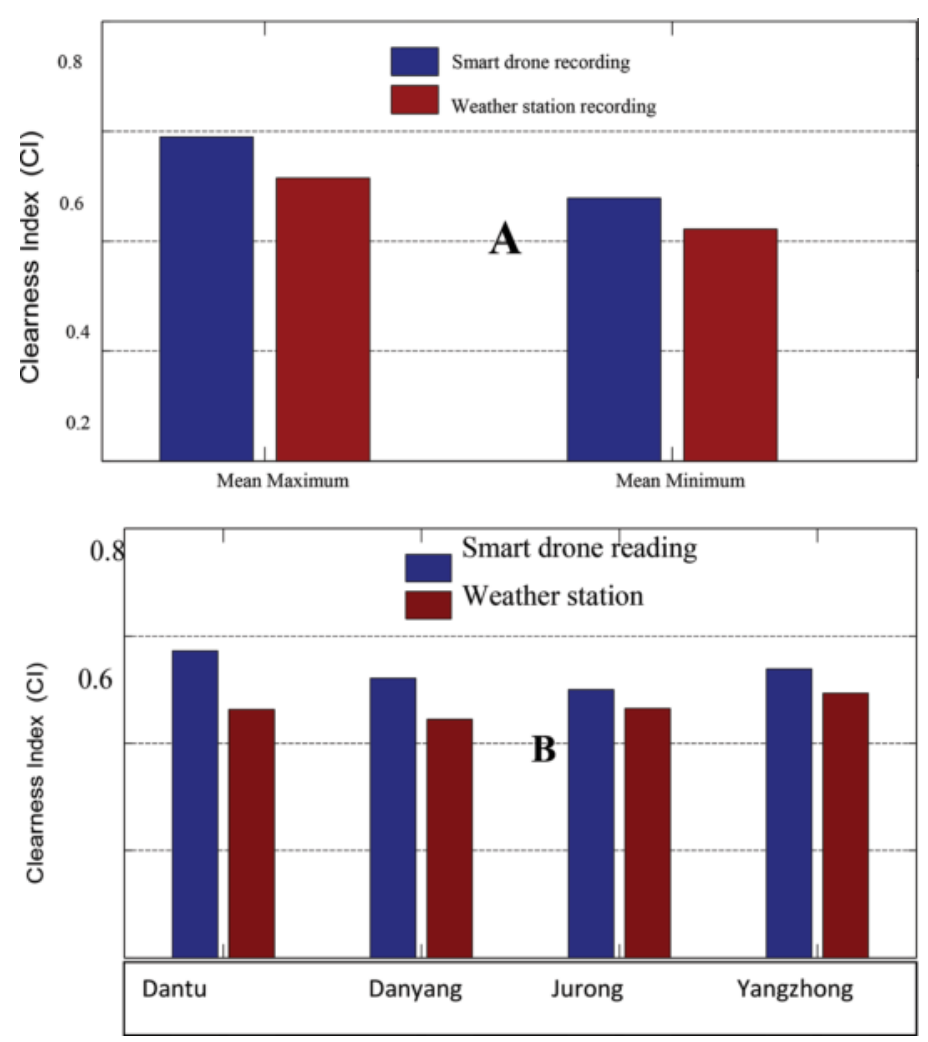

Figure 5. Clearness index (CI) over Zhenjiang: (a) represents the monthly mean maximum and minimum CI over the country and (b) represents clearness index (CI) for all the four districts (agro-ecological zones).

that the amount of solar radiation on a horizontal surface is sufficient for solar energy utilization in Zhenjiang city.

The weather station clearness index is relatively low compared with the estimated clearness index by the Smart Drone. This is expected since the Meteosat-7 satellite observed Global Horizontal Irradiation, (GHI) by the clear-sky model developed by the SWERA-partner SUNY (State University of Albany, New York), which was implemented by [13].

\section{Conclusion}

It is expected that, based on the autopilot data already generated, the Smart Arduino Sensor Integrated Drone will predict the average means of temperature, rainfall, wind (direction and speed) solar patterns of Zhenjiang community in China. This Smart Drone in agriculture is a big boost to farmers because it carries the potential of completely transforming and revolutionizing the farming and agriculture industry. 
Weather parameter reading, soil health scans, monitoring crop health, applying fertilizers and watering the fields, even tracking weather and estimating yields, and then collecting the data and analyzing it for prompt action are some elements considered in this ongoing project.

All in all, this Smart Arduino Integrated Drone can mechanize every step of farming and eliminate the costs of human errors and enable farmers to react quickly to threats (such as drought conditions and flood), helping with maximization of income and returns on investment crop productivity.

This Smart Drone in agriculture is a big boost to farmers because it carries the potential of completely transforming and revolutionizing the farming and agriculture industry.

\section{Author details}

Hanping Mao, Oppong K. Paul*, Ning Yang and Lin Li

*Address all correspondence to: lifejnr@yahoo.com

School of Agricultural Equipment Engineering, Jiangsu University, Zhenjiang, Jiangsu, P.R China

\section{References}

[1] Acheampong AA, Fosu C, Amekudzi LK, Kaas E. Perceptible water comparisons over Ghana using PPP techniques and reanalysis data. 2017;6(3):449

[2] Lowe EF, Battoe LE, Coveney MF, Schelske CL, Havens KE, Marzolf ER, Reddy KR. The restoration of Lake Apopka in relation to alternative stable states: An alternative view to that of Bachmann et al. (1999). Hydrobiologia. 2001;448(1-3):11-18

[3] Siqueira MFD, Peterson AT. Consequences of global climate change for geographic distributions of cerrado tree species. Biota Neotropica. 2003;3(2):1-14

[4] Segond ML, Tabary P. 10.5 quantitative precipitation estimations from operational polarimetric radars for hydrological applications. 2007

[5] Herrmann JW, Lin E, Al E. Affordable space systems manufacturing: Intelligent synthesis. Paper presented at the CD-ROM ASME Design Engineering Technical Conferences \& Computers \& Information in Engineering Conference; 2001

[6] Clark DR, Meffert C, Baggili I, Breitinger F. DROP (DRone Open source Parser) your drone: Forensic analysis of the DJI Phantom III. Digital Investigation. 2017;22:S3-S14

[7] Havenith MN, Yu S, Biederlack J, Chen NH, Singer W, Nikolić D. Synchrony makes neurons fire in sequence, and stimulus properties determine who is ahead. Journal of Neuroscience, The Official Journal of the Society for Neuroscience. 2011;31(23):8570 
[8] Arakliotis S, Nikolos DG, Kalligeros E. LAWRIS: A Rule-Based Arduino Programming System for Young Students. Paper presented at the International Conference on Modern Circuits and Systems Technologies; 2016

[9] Cerveny R. Hamilton and the hurricane. Weatherwise. 2016;69(5):42-48

[10] Tubiello FN, Amthor JS, Boote KJ, Donatelli M, Easterling W, Fischer G, et al. Crop response to elevated CO and world food supply: A comment on "Food for Thought..." by Long et al., Science 312:1918-1921. European Journal of Agronomy. 2007, 2006;26(3):215-223

[11] Curry JM, Ohnson ER, Tarnes JH. Effect of dropped plies on the strength of graphiteepoxy laminates. AIAA Journal. 2015;30(2):449-456

[12] Toledo-Aceves T, Swaine MD. Biomass allocation and photosynthetic responses of lianas and pioneer tree seedlings to light. Acta Oecologica. 2008;34(1):38-49

[13] Imam S, Yilmaz S, Sohmen U, Gorzalski AS, Reed JL, Noguera DR, Donohue TJ. iRsp1095: A genome-scale reconstruction of the Rhodobacter sphaeroides metabolic network. BMC Systems Biology. 2011;5(1):116 
